\title{
THE HOSPITABLE COMMUNITY: A TRAUMA-SENSITIVE ENVIRONMENT FOR CHILDREN AND YOUTH
}

\author{
Ron Bruner \\ Westview Boys' Home, Hollis, OK
}

In his epic tale, the Odyssey, Homer drives the hero Odysseus from Troy to one inhospitable beach after another in his ten-year quest to return home to Ithaca (Homer, 1995). Over the course of his journey, fickle deities strip this wealthy, privileged, and wise warrior of his resources, relationships, and even hope. Odysseus is separated from his royal father, noble wife, and promising son. Ultimately, he is an outsider, naked and weak as a child; Odysseus literally becomes a "nobody" (Homer, 1995, 9:366). He stays in many places, yet in the best of them he longs for family and home. Throughout the narrative, Homer marks the quality of character of each person Odysseus and his son Telemachus encounter by the quality of hospitality that they extend to these weary travelers (Arterbury, 2005, p. 32; Bolchazy, 1977, p. 2; Louden, 2011, p. 32). Both Siren and Cyclops are dangerous because their power toward outsiders serves their hunger instead of that of their guests. In contrast, the virtuous Nestor and Menelaus open their homes, provide for and protect their guests, and, to the fullest extent of their considerable power, send them toward a hopeful future.

In a way that is unfortunately similar to the path of Odysseus, some at-risk children drift from house to house wondering if they will ever be able to find their way home. Though most placements in foster and residential care are successful, some result in one disrupted placement after another (Rosenthal, 2011; Sinclair, Wilson, \& Gibbs, 2005, p. 136). Perpetual outsider status deepens the struggle of children coping with trauma (Herman, 1992, p. 52). At the mercy of well-intentioned forces that they sometimes see as fickle, these young people find themselves separated from family and cast as outsiders upon the doorsteps of a sequence of strangers, whether in foster care or residential child care. Some hosts are hospitable; others, at least to these young wanderers, appear hostile to their culture, family, or even their person (Payne, Devol, \& Smith, 2001, pp. 39-48). This failure of hospitality frequently results in another disrupted placement, which can hinder the young person's progress toward healing from trauma, a clear identity, or a sustainable future (Sinclair et al., 2005, p. 138). It can also stimulate problem behavior not previously present (Strijker, Knorth, \& Knot-Dickscheit, 2008). However, where homes offer a virtuous quality of welcome, youth can find healing and hope.

The outsider status of these children provides a clue as to the best strategy to help them. Hospitality, in the ancient Mediterranean sense of the word, is a virtue and practice that welcomes, protects, cares for, and relaunches the troubled outsider. Hospitality as a cross-cultural tool has entered the conversation in many contemporary fields of study: social work (e.g., Sackreiter \& Armstrong, 2010; Sirriyeh, 
2013), education (Langmann, 2010; McAvoy, 1998), philosophy (Derrida \& Dufourmantelle, 2000; Dikeç, Clark, \& Barnett, 2009), and theology (Russell, 2009). Kouri suggests that the concept of hospitality is the way forward in youth care (Kouri, 2012). The practice of hospitality also has prominent exemplars among diverse faith perspectives: Buddhist (De Béthune, 2007), Christian (Arterbury, 2005), Muslim (Akpinar, 2007; Shryock, 2009), Jewish (J. M. Cohen, 2006), and polytheist (Bolchazy, 1977). From the viewpoint of those who do not believe in a god, Derrida equates hospitality with ethical behavior (Derrida, 2001).

Based on the ancient practice of hospitality, this work describes a trauma-sensitive environment for at-risk youth living in out-of-home placements. This methodology was designed and tested in a qualitative research project conducted at a residential childcare facility caring for at-risk boys (Bruner, 2010). Hospitable communities well serve the needs of traumatized children and youth, whether they take the shape of foster families or residential child care facilities. The objective is to help these nontraditional care giving families find balance in how they care for troubled youth. How ought such families open their homes to children who often have very different boundaries? How might families remain vulnerable enough to hear the traumatic narratives of these youth and yet maintain a safe space for others? How can adults avoid dwelling on the difficult truths of these young lives and work with these youth to find hope instead? This study seeks a trauma-sensitive balance of these factors.

\section{Definitions}

In this work the term community will refer to the collection of persons providing care to and sharing space with children, whether family, residential child care team, or treatment team. By its practice of hospitality, the community shapes the welcome that youth feel in its midst. We will use the definition of hospitality given by Henri Nouwen:

Hospitality, therefore, means primarily the creation of a free space where the stranger can enter and become a friend instead of an enemy. Hospitality is not to change people, but to offer them space where change can take place. It is not to bring men and women over to our side, but to offer freedom not disturbed by dividing lines. It is not to lead our neighbor into a corner where there are no alternatives left, but to open a wide spectrum of options for choice and commitment (1975, pp. 71-72).

Hospitality is one of several virtues, with virtue meaning "persistent excellence in being for the good" (Adams, 2006, p. 11). Virtue is not merely doing the right thing with the right motive; it is doing something repeatedly and consistently enough to rise to a level of excellence. A vice is not a momentary lapse, but the continued practice of that which is not good. An ideology is a framework that 
values specific perspectives and virtues while deprecating certain vices. However, many different ideologies might value a specific virtue like hospitality or respect. Such virtues can empower cross-cultural dialogue. Character is the sum total of the virtues and vices of an individual or a community. Virtuous individuals and communities, knowingly or not, read and interpret their context using a hermeneutic that coheres with their ideology. Hermeneutics is the individual and communal interpretation of texts and experience, simultaneously art and science (Gerkin, 1984, pp. 19-20). The term child will serve for both children and adolescents in this study.

\section{An Overview of Trauma Treatment}

Since Judith Herman's foundational work in trauma (1992), therapists have sought to identify effective treatments to help the victims of trauma move forward. Initially perceived to be an adult diagnosis, researchers eventually established the debilitating effects of trauma in the lives of children and began to develop evidence based approaches for treatment specifically for children and adolescents (J. A. Cohen, Mannarino, \& Deblinger, 2006). Most of these approaches follow a course of treatment that is a variation on the theme established by Herman; they seek to: establish safety for all present; remember and mourn the trauma; and finally, reconnect the victim with life on the far side of trauma (1992, p. 155). Most trauma to children occurs within a relationship, yet it is within relationships-with a therapist, family, or community - that healing from trauma must take place (Kinsler, Courtois, \& Frankel, 2009). For healing to begin, most researchers agree that the prime virtue of the environment surrounding the child must be safety (Ford \& Cloitre, 2009, p. 67). The child must perceive the therapist to be a safe and trustworthy person, yet the child must perceive their community to be safe as well or progress on any treatment plan will be halting. Safety plans can ensure that the child feels safe throughout the course of treatment; the child also ought to acquire personal safety skills as they prepare to leave therapy (J. A. Cohen et al., 2006, pp. 157-165).

Other virtues besides safety are necessary for a therapeutic relationship and community. For example: "Healing of complex and chronic trauma . . occurs in safe, dependable, kind, and bounded relationships" (Kinsler et al., 2009, p. 183). Since most researchers do not prescribe communal virtues for a treatment milieu, how might such a virtue list be constructed? One way is in the identification of virtues underlying treatment principles. Principles define practices that, when done persistently and with excellence become virtues. Ford and Cloitre prescribe a useful set of principles for psychotherapy with traumatized children: (a) establish safety; (b) open relational bridges; (c) design diagnosis and treatment relationally; (d) focus on strengths (not deficits); (e) build self-competency; (f) choose where, when, and how to discuss traumatic memories; and (g) avoid or cope with relational discontinuity (Ford \& Cloitre, 2009). Since the child's community, or treatment milieu, should cohere with the therapeutic relationship, that reality would require the community to exhibit virtues consistent with such practices: (a) safe; 
(b) open, to new or deeper relationships; (c) flexible, especially to the needs of the child; (d) truthful and hopeful; (e) equipping; (f) vulnerable, in the healthy sense of the word; and (g) persistent. These virtues are the virtues of a hospitable community.

\section{Out-of Home Placements and the Broader Moves of Hospitality}

Ancient Mediterranean hospitality serves as both a metaphor and practice positively framing the care of children in out-of-home placements. In ancient hospitality there were three broader moves to the hospitable event: the welcoming of the unknown stranger, the dwelling together in conversation around a table, and the providential sending forth to the next place on the traveler's journey (Bruner, 2010). In brief, the three movements of ancient hospitality are: welcome, abiding, and sending forth. The three stages of hospitality resonate with the three stages of trauma recovery:

1. establishing safety for all present,

2. coping with remembering and mourning the trauma, and

3. reconnecting youth with life on the far side of trauma (Herman, 1992, p. 155).

In ancient hospitality, the welcome was key. An outsider would enter a community, find greeting from a host, who would greet the guest, bring them into his or her home, see to his or her needs, and - only after the outsider was bathed, clothed, and well-fed-inquire into the outsider's identity and background (Homer, 1995, 1.120-210; 3.29-100; 4.20-182; 5.85-95; 6.13-320; 7.140-315; 14.30-120). Depending upon his or her needs, guests would remain under the roof of the host, sharing shelter, resources, and their personal narrative until the guest was ready to move on. Then, to empower his or her guest's hope of making their destination, the host would equip the guest with resources and often send an escort to take his or her guest onward (Homer, 1995, 3.346-498; 8.25-45; 13.47-92). These practices clearly connect with out-of-home care.

Yet those families who willingly let any stranger sit at their table soon discover that hospitality is more complex than sharing a meal. Both ancient and contemporary understandings of hospitality involve a host encountering a guest. However, virtuous hospitality is the encounter of "one" with the "other," with the differences of culture, context, perspective, language, and ideology to be bridged. Virtuous hospitality is a hospitality of ideas. The religious faith or deep-seated morality that calls many couples to become care givers can either fund hospitality or become the source of identity and boundary issues that can complicate or terminate foster placements. Rules-based systems of checks on such xenophobic behavior are not helpful because of the infinite number of possible situations out-of-home placements can generate (Rose, 1999, pp. 181-183). A simpler and more flexible frame- 
work, a hermeneutic of situations might be easier to remember and more helpful in practice.

\section{Hospitality and Hermeneutics}

Policies and procedures are important in establishing a trauma-sensitive environment; yet each day brings new situations to caregivers. It is infeasible for agencies to constantly update manuals to deal with these new realities (Bloom, 1997, p. 122). Even if a community were able to attempt the construction and maintenance of such a document, its size would soon exceed what a human could readily recall or enact. What caregivers need instead is an agreed-upon hermeneutic that allows them to read their situation and respond appropriately (Gerkin, 1984). Russell clearly defined a hermeneutic of hospitality in Just Hospitality: "Our hermeneutic of hospitality can (1) pay attention to the power quotient involved in what is said and who is saying it, (2) give priority to the perspective of the outsider, and (3) rejoice in God's unfolding promise" (Russell, 2009, p. 43). Bruner has subsequently broadened and balanced Russell's categories and defended their use in a child care context (Bruner, 2010). In Bruner's hermeneutic, a community must read its context and frame its actions with a cluster of virtues that make hospitality virtuous, effective, and just: safety, vulnerability, maintenance of identity, openness, truthfulness, and hopefulness. This virtue list is very similar to the list of virtues describing a community appropriate for traumatized youth (see above).

When first considering vices and virtues in any hermeneutic, it might seem that they exist in binary pairs: each virtue has its opposing vice. For example, courage and cowardice stand in opposition. Aristotle's solution is more complex; he asserts the existence of the virtuous mean (Nicomachean Ethics, II, 8 \& 9). Cowardice may be the vice of inability to function despite the presence of fear, while courage is the virtue of being able to function despite the presence of fear, yet there is a third point. Rashness is the vice that results when one acts in the face of a risk that should not be ignored (see figure 1 - Aristotle's Virtuous Mean).

For example, if someone were to dash out in front of a moving car in order to pull a child out of the way, most observers would count that as courage. If the same person ran out in front of a car to retrieve a basketball, most would mark that as rashness. 


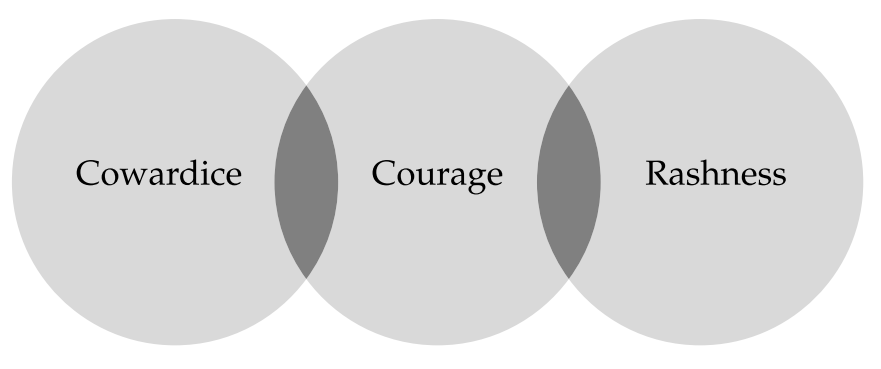

deficiency excess

Figure 1: Aristotle's Virtuous Mean

Adams suggests, using courage as an example, that virtues are contextual and modular. The kinds of courage that constitute virtue in intellectual, physical, emotional, and social domains are categorically different and depend upon those specific contexts (Adams, 2006, pp. 179-184). The courage required to rescue the wounded from the battlefield is different than the courage required to care for the traumatized at the dinner table. The differences in these types of courage reveal the modularity of virtue; there are modules of virtue that form the larger virtue (Adams, 2006, pp. 125-130). I assert that risking vulnerability is a module of courage, a definite move away from cowardice. Simultaneously, maintaining some degree of safety is the module of virtue empowering courage to avoid rashness. Safety and vulnerability are virtues constituting modules of the virtue of courage. These modular virtues must be kept in tension with one another for courage to be virtuous. That tension is not static, but constantly changes with variations in the context, circumstances, participants, and resources.

\section{A Hermeneutic of Hospitality}

In a similar way, Bruner's hermeneutic has three lenses, each lens holding two hospitable virtues in tension (see Figure 2: Tensive Hospitable Virtues). Use of these lenses allows the individual or the community to read their situation and evaluate whether the traumatized guest is experiencing just hospitality. If not, then the lenses help identify what the problematic issues might be. An examination of each of the three lenses follows. 


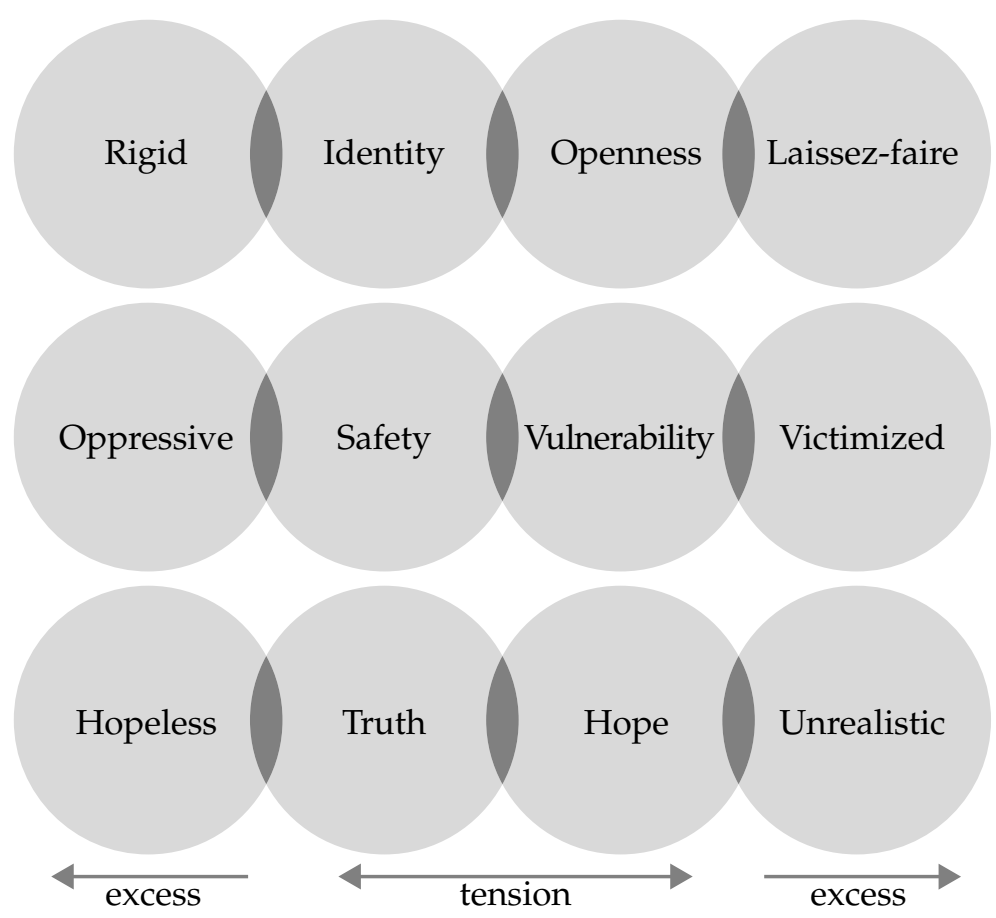

Figure 2: Tensive Hospitable Virtues

Openness and identity. There must be an understanding of the balance between openness and the identity in the relationship between the community and outsider (Russell's "perspective of the outsider"). In this tension, family members and outsiders share access, culture, voice, and relationship. It is obvious that a community must be open to receive a child in an out-of-home placement; no less important is the necessity of the child to be open, despite differences, to that placement. Lartey reminds those engaged in intercultural work that all humans are in some aspects "like all others," "like some others," and "like no other" (Lartey, 2003). Although caretakers cannot change their culture or core identity, they can be open enough to provide a "symphony of support" for outsider children (J. A. Cohen et al., 2006, pp. 40-41). Not only must the host community be sensitive to the culture of the traumatized youth in its midst, it must be aware that trauma may reveal itself in different culturally-normed ways because of the young person's native culture. At the same time, the child must choose to be open and accommodating to a new environment with different boundaries. Neither host nor guest must be so "open" to the other, though, that he or she loses his or her identity or personal boundaries. Equating the person without boundar- 
ies to a person without identity, a nobody, Nouwen asserts, "No real dialogue is possible between somebody and a nobody" (Nouwen, 1975, p. 99). However, host and guest must realize that the very natures of hospitality and relationship are such that presence of the "other" in hospitality will change both.

Safety and vulnerability. The community must measure the tension between safety and vulnerability in the situation (the "power quotient" for Russell). Human beings are essentially dangerous. The experience of most humans warns them that those proven dangerous often repeat dangerous behaviors; in the eyes of some traumatized youth, almost anyone is potentially dangerous (Kinsler et al., 2009, pp. 184-185). Therefore, the radical openness to reconciliation and hospitality described above risks the repetition of violence from either the incorrigible perpetrator or the fearful and defensive victim. Somehow the community and the child must negotiate a balance of safety and vulnerability. Safety is a condition and virtue more broadly descriptive of the human need to avoid suffering, whenever possible, for self or another. Safety is not just the avoidance of pain caused by the abuse of power; it is also security against injury from unintentional, neglectful, or self-inflicted dangers, and providence for those resources and relationships that are life-giving.Vulnerability is more than dropping one's defenses; it is not weakness (Brown, 2012, pp. 32-56). It is the willingness to hear, see, receive, sympathize, and possibly even suffer with or for another.

One way to balance safety and vulnerability is through an ongoing conversation about reasonable expectations; at times this might take the form of a covenant (Bruner, 2010). The objective is for the hospitable family and guest to safely share resources, including possessions, space, and power. Care givers, though, should not be surprised when a child well into the healing process chooses to test, sometimes severely, the balance of safety and vulnerability (Perry \& Szalavitz, 2006). Rose gives a helpful metaphor describing the phenomenon:

An individual's refusal to acknowledge love or nourishment may mask a state of unconscious terror. As his or her frostbitten emotions begin to unfreeze in the consistent warmth of the therapeutic relationship, pain rather than absence of feeling is bound to make itself felt. The response may well be an increase in extremely destructive behavior. The journey from a frozen childhood and adolescence to a creative and loving adulthood, will inevitably be a passage of fear and grief. Thus the staff, with their complementary therapeutic task, cannot avoid daunting emotions either (Rose, 1999, p. 180).

Virtuous hospitality copes with this pain, deflects and corrects the behavior, and gradually equips the young guest with the social and psychological resources needed for the journey ahead. 
Truthfulness and hopefulness. Communities must maintain the tension between truthfulness and hopefulness (in Russell's hermeneutic, "unfolding promise"). Gradually bringing truth and hopefulness into balance turns the attention of the traumatized youth from past wounds to an improved level of functioning in the present and the possibility of personal transformation in the future. The persistent problem is discovering and dealing with the traumatic truth without being defined or limited by it. Helping young people build successful lives is frequently much more about helping them use their strengths so as to minimize their weaknesses and create an identity not defined by their dysfunction (Peterson \& Seligman, 2004). After understanding and acknowledging that the trauma is not their fault, the child can look hopefully toward a future where they are selfregulating (Ford \& Cloitre, 2009) and empowered to secure safety for themselves (Cohen et al., 2006).

\section{Shifting Tensions in Hospitality}

It should be noted that the tension point may be at very different places for the community and a particular individual. The parent of a care giving family may feel no threat from the acting-out behavior of a traumatized youth struggling with the healing process. However, there may be younger children (biological, foster, or residential placements) in that community for whom such behavior may represent a danger of some extent. Appropriate safety plans for all involved may allow the hospitable situation to continue uninterrupted even though strained. Kumpfer and Summerhays give this advice:

No child today is beyond risk; no child is, or could be, completely protected. Exposure to moderate stressors, challenges, and risks can help children develop effective coping responses and resilience. Wise parents naturally titrate a child's temperament, capabilities, and resilience with levels and types of stressors before allowing or encouraging new challenges (Kumpfer \& Summerhays, 2006, p. 152).

Children are not the only vulnerable humans; if, for example, the type of trauma experienced by the child is too similar to the trauma experience of one of the adults present, then that placement may or may not be optimal for guest or host.

The completed hermeneutic of hospitality consists of three sets of tensive dyadic virtues: security and vulnerability, identity and openness, and truth and hope. Although all of these virtues have value throughout any phase of hospitality, each of these sets of tensive virtues is more prominent within one of the three larger moves of hospitality: welcome, staying, and sending. The virtues of identity and openness shape the quality of welcome a community shows an outsider and may even determine which outsider might gain entry. When the community properly holds identity and openness in tension, even a person who might be considered an 
adversary of the community can find welcome and voice within hospitality without endangering the identity of the community. As host and guest dwell together in the hospitable event, the virtues of safety and vulnerability rise to prominence. When the community properly shares resources with its guests, most prominently voice and power, then the balance between safety and vulnerability allows healthy relationships to form and empowers the lives of both host and guest to prosper. Finally, in order for the sending forth of the guest to bring joy and sustainable life for host and guest, somehow he or she must balance truth and hope.

\section{Comparisons to Other Models}

The concept of hospitable community empowers the ongoing quality improvement of a community of care, provides a common language for dialogue and decision making, and reduces stress for most care givers (Bruner, 2010). The hospitable community constitutes an environment similar to other successful treatment milieus. The Sanctuary Model ${ }^{\circledR}$, for example, seeks to establish a safe environment for both client and professional (Abramovitz \& Bloom, 2003). Sandra Bloom created this model for use with adult trauma victims (Bloom, 1997), but others have now adapted it for use in youth residential programs (Rivard et al., 2004). They use this nonlinear model to pursue safety, emotional management, loss work, and future for both clients and the treatment community, thus, the mnemonic: SELF (Foderaro \& Ryan, 2000; McCorkle, 2007). Like the Sanctuary Model, the hospitable community pursues the same tasks in the three moves of hospitality. The community of hospitality welcomes others by balancing the safety found in Sanctuary's SELF with vulnerability, provides abiding space for emotional management and grief in a space balanced in openness and identity, and sends forth children, aware of the truth of their past, moving on to a hopeful future.

The concept of hospitable community also provides Haigh's five ingredients for a treatment community, which Haigh places in a "developmental" order: attachment, containment, communication, involvement, and agency (Haigh, 1999). In a hospitable community, welcome involves the first element; abiding facilitates the second, third, and fourth; and agency is prominent in sending forth.

\section{Conclusion}

The aim of this study has been to present an overview of concept of hospitality for constructing a healthy milieu for the care of children who have experienced trauma. The actual practice of hospitality in such a context requires complete coherence and total community commitment, including that of the leadership of the community and every person living within it. A community must commit to and engage in considerable dialogue and preparation to implement the concept; that process is more likely to be successful when it begins with the basic concepts. Faith communities may choose to construct their practices based on the narratives of hospitality particular to their faith; as mentioned above, most faith communities have 
exemplars and stories to access.

The practice of hospitality empowers caregivers to share an environment with traumatized youth in which he or she can find a safe welcome, remain to recover from his or her trauma, then experience a clean launch into a resilient life. The use of a hermeneutic of hospitality empowers the community to create a hospitable environment, share realistic expectations of what life together might be like, reduce stress for host and guest, and prevent untimely exits and unnecessary additional placements. Hospitality provides an important and empowering resting place for young weary travelers on their odyssey to safely return home and finally rejoin family.

\section{References}

Abramovitz, R., \& Bloom, S. L. (2003). Creating sanctuary in residential treatment for youth: from the "well-ordered asylum" to a"living-learning environment." The Psychiatric Quarterly, 74(2), 119-135.

Adams, R. M. (2006). A theory of virtue: Excellence in being for the good. Oxford: Clarendon.

Akpinar, S. (2007). Hospitality in Islam. Religion East \& West (7), 23-27.

Arterbury, A. (2005). Entertaining angels: Early Christian hospitality in its Mediterranean setting. Sheffield, England: Sheffield Phoenix.

Bloom, S. L. (1997). Creating sanctuary: Toward the evolution of sane societies. New York, NY: Routledge.

Bolchazy, L. (1977). Hospitality in early Rome: Livy's concept of its humanizing force. Chicago, IL: Ares.

Brown, B. (2012). Daring greatly: How the courage to be vulnerable transforms the way we live, love, parent, and lead. New York, NY: Penguin.

Bruner, R. (2010). Communally discerning a covenant of hospitality for the care of children at Westoiew Boys' Home. (DMin thesis), Abilene Christian University, Abilene, TX.

Cohen, J. A., Mannarino, A. P., \& Deblinger, E. (2006). Treating trauma and traumatic grief in children and adolescents. New York, NY: Guilford. 
Cohen, J. M. (2006). Abraham's hospitality. Jewish Bible Quarterly, 34(3), 168-172.

De Béthune, P. F. (2007). Interreligious dialogue and sacred hospitality. Religion East \& West (7), 1-22.

Derrida, J. (2001). On cosmopolitanism and forgiveness (M. Dooley \& M. Hughes, Trans.). New York, NY: Psychology Press.

Derrida, J., \& Dufourmantelle, A. (2000). Of hospitality. Redwood City, CA: Stanford University Press.

Dikeç, M., Clark, N., \& Barnett, C. (2009). Extending hospitality: Giving space, taking time. Paragraph, 32(1).

Foderaro, J. F., \& Ryan, R. A. (2000). SAGE: Mapping the course of recovery. Therapeutic Communities: The International Journal for Therapeutic and Supportive Organizations, 21(2), 93-104.

Ford, J. D., \& Cloitre, M. (2009). Best practices in psychotherapy for children and adolescents. In C. A. Courtois \& J. D. Ford (Eds.), Treating complex traumatic stress disorders: An evidence-based guide (pp. 59-81). New York, NY: Guilford.

Gerkin, C. V. (1984). The living human document: Re-visioning pastoral counseling in a hermeneutical mode. Nashville, TN: Abingdon.

Haigh, R. (1999). The quintessence of a therapeutic environment: Five universal qualities. In P. Campling \& R. Haigh (Eds.), Therapeutic communities: Past, present, future (pp. 246-257). London: Jessica Kingsley.

Herman, J. (1992). Trauma and recovery: The aftermath of violence from domestic abuse to political terror. New York, NY: Basic.

Homer. (1995). The Odyssey (Loeb Classical Library). Cambridge, MA: Harvard University Press.

Kinsler, P. J., Courtois, C. A., \& Frankel, A. S. (2009). Therapeutic alliance and risk management. In C. A. Courtois \& J. D. Ford (Eds.), Treating complex traumatic stress disorders: An evidence-based guide (pp. 183-201). New York, NY: Guilford.

Kouri, S. (2012). Child and youth care to-come. Child \& Youth Services, 33(3/4), 206-236. doi: 10.1080/0145935X.2012.745782 
Kumpfer, K. L., \& Summerhays, J. F. (2006). Prevention Approaches to Enhance Resilience among High-Risk Youth. Ann N Y Acad Sci, 1094(1), 151-163. doi: 10.1196/annals.1376.014

Langmann, E. (2010). Welcoming difference at the limit of tolerance education. Philosophy of Education Yearbook, 337-345.

Lartey, E. Y. (2003). In living color: An intercultural approach to pastoral care and counseling (Second ed.). Philadelphia, PA: Jessica Kingsley.

Louden, B. (2011). Homer's Odyssey and the Near East. Cambridge: Cambridge University Press.

McAvoy, J. (1998). Hospitality: A feminist theology of education. Teaching Theology \& Religion, 1(1), 20.

McCorkle, D., \& Yonosy, S. (2007). When loss gets lost: using the S.E.L.F. model to work with losses in residential treatment. In A. L. Vargas \& Bloom, S. L. (Eds.), Loss, Hurt and Hope: The complex issues of bereavement and trauma in children (pp. 116-141). Newcastle, UK: Cambridge Scholars Press.

Nouwen, H. (1975). Reaching out: the three movements of the spiritual life. New York, NY: Doubleday.

Payne, R., Devol, P., \& Smith, T. (2001). Bridges out of poverty: Strategies for professionals and communities. Highlands, TX: aha! Process.

Perry, B. D., \& Szalavitz, M. (2006). The boy who was raised as a dog: and other stories from a child psychiatrist's notebook: What traumatized children can teach us about love, loss, and healing. New York, NY: Basic.

Peterson, C., \& Seligman, M. E. P. (2004). Character strengths and virtues: A handbook and classification. Oxford: American Psychological Association.

Rivard, J. C., McCorkle, D., Duncan, M. E., Pasquale, L. E., Bloom, S. L., \& Abramovitz, R. (2004). Implementing a Trauma Recovery Framework for Youths in Residential Treatment. Child \& Adolescent Social Work Journal, 21(5), 529-550.

Rose, M. (1999). Children and adolescents: The renaissance of heart and mind. In P. Campling \& R. Haigh (Eds.), Therapeutic Communities: Past, Present, and Future (pp. 174-185). London: Jessica Kingsley. 
Rosenthal, J., \& Villegas, S. (2011). Placement stability for children adjudicated as dependent: A survival analysis of a state database. Journal of Public Child Welfare, 5, 67-86.

Russell, L. M., Clarkson, J., Shannon, \& Ott, M. (2009). Just hospitality: God's welcome in a world of difference. Louisville, KY: Westminster John Knox.

Sackreiter, A., \& Armstrong, T. D. (2010). Radical hospitality: Welcoming the homeless stranger. Social Work \& Christianity, 37(2), 204-228.

Shryock, A. (2009). Hospitality lessons: Learning the shared language of Derrida and the Balga Bedouin. Paragraph, 32(1), 32-50. doi: 10.3366/ E026483340900039X

Sinclair, I., Wilson, K., \& Gibbs, I. (2005). Foster placements: Why they succeed and why they fail. London: Jessica Kingsley.

Sirriyeh, A. (2013). Hosting strangers: hospitality and family practices in fostering unaccompanied refugee young people. Child \& Family Social Work, 18(1), 5-14. doi: 10.1111/cfs.12044

Strijker, J., Knorth, E. J., \& Knot-Dickscheit, J. (2008). Placement history of foster children: a study of placement history and outcomes in long-term family foster care. Child Welfare, 87(5), 107-124. 